\title{
Impact of Outdoor Space towards the Elderly Wellbeing at Rumah Ehsan Kuala Kubu Bharu
}

\author{
Ahmad Ridzwan Othman, Fikri Fadzil \\ Faculty of Architecture, Planning and Surveying, \\ Universiti Teknologi MARA, Shah Alam, Malaysia \\ dwan_arc7@yahoo.com
}

\begin{abstract}
There is a correlation between the wellbeing of residents of elderly care centre with a well-designed outdoor space. The study was to assess the impact of outdoor space towards the elderly wellbeing in a selected care centre in Malaysia. The focus was on how the elderly physically, emotionally, psychologically and socially behave towards their environment. The investigation is expected to raise awareness amongst the elderly, public and even professionals regarding the significance and implication of having well-designed outdoor spaces at elderly care centre. .
\end{abstract}

Keywords: Outdoor space; elderly; wellbeing, space design

eISSN 2398-4295 @ 2018. The Authors. Published for AMER ABRA cE-Bs by e-International Publishing House, Ltd., UK. This is an open-access article under the CC BY-NC-ND license (http://creativecommons.org/licenses/bync-nd/4.0/). Peer-review under responsibility of AMER (Association of Malaysian Environment-Behaviour Researchers), ABRA (Association of Behavioural Researchers on Asians) and $c E-B s$ (Centre for EnvironmentBehaviour Studies), Faculty of Architecture, Planning \& Surveying, Universiti Teknologi MARA, Malaysia.

DOI: http://dx.doi.org/10.21834/ajbes.v3i12.126 


\subsection{Introduction}

As Malaysia progresses to become a high-income nation by the year 2020, the ageing population will continue to increase, following the trend set by current developed countries such as Japan (Abdul Rahim 2006). Hence, catering for the needs of the elderly now is crucial for the country as they will form a significant portion of the society in the future. Elderly care centres in Malaysia usually pay little attention to their outdoor spaces - in terms of design, activities and general maintenance - which result in the elderly having to spend most of their time indoors.

In architecture, an outdoor space may refer to verandah, courtyard, garden or any space that is open towards the outdoor environment. Based on the definition made by the World Assembly on Ageing, in the year 1982 in Vienna, the elderly is defined as the group of people of age 60 and above. Elderly care centres, on the other hand, is a place of residence for elderly people who require care but not necessarily have significant deficiencies with activities of daily living. According to Lovering (1990), there is a growing interest in creating outdoor space to complement the interior program in nursery homes despite the lack of design principles. Based on the study by Brawley (1992), there is correlation between the well-being of residents of nursery homes with a well-designed outdoor space. He claims that having outdoor space has the potential to prevent or deal with the loss of human functions among the elderly such as hearing, vision, mobility or social behaviour.

\subsection{Statement of the Problem}

The importance of accessibility, safety, independence, orientation, privacy and sociability in elderly spaces, either they are indoors or outdoors, are already proven in various studies (Carstens 1985, Howell 1980). However, designers rarely apply their knowledge in designing communities for the aged (Lawton 1990). In fact, designers typically give little to no considerations to the design of outdoor environments for the elderly (Lovering 1990). Some outdoor environments are better design-wise compared to the others but remain unused among the residents. Generally, designers of elderly communities either lack an understanding of the importance of outdoor environments to the elderly population or lack an understanding of the clients themselves. This results in unsuccessful designs.

\subsection{Purpose of the Study}

The purpose of this study was to identify and understand the need of having outdoor space in care centres; how the elderly physically, emotionally, psychologically and socially behave towards their environment. From the investigation, it is expected to raise awareness amongst the elderly, public and even professionals regarding the significance and implication of having well-designed outdoor spaces at care centres.

\subsection{Aim and objectives of research}

The aim of the study is to investigate the effects of outdoor spaces towards the elderly in a care centre through conducting a survey among the elderly living. From the survey, it would be possible to gauge the level of awareness among the elderly on the significance of human 
environments and importance in the process of design. In line with the aim, the objectives of the study are listed below:

- To identify the existing design of outdoor space in the elderly care centre

- To determine whether the design is suitable and beneficial for the elderly well-being

- To provide guidelines for future designs of outdoor spaces

\subsection{Literature Review}

\subsection{The Health, Habits and Social Behaviours of the Elderly}

The levels of health, habit as well as surroundings of the elderly are important factors which need to be considered when designing buildings or facilities for them. This is to ensure the design suits their needs well. Heikennen (1989) stated:

"There are at least three components concerning both health and functional capacity - physical, mental and social - that we should take into consideration. If health is conceived as a dynamic equilibrium, dysfunction in any angle component will be reflected through the whole individual in terms both of how they manage everyday life and how the perceive their health."

This is further explained in Figure 1 which displays physical dysfunction or the dwindling state of physical capabilities will give direct impact on the mental quality, hence resulting in the changes of social behaviours of the elderly. Furthermore, Heikennen (1989) stated:

"It is that continuity, coordination and correct timing are important service provision, but at the same time these are criteria that are very difficult to meet in service systems."

Williams (1995) explained that ageing does not only involve physical and mental changes process but also gives direct consequences to the social life of an individual elderly. $\mathrm{He}$ stated:

"Old age, too, brings in some changes in attitude and behaviour. And important example is the phenomenon of non-reporting of symptoms or problems and this is significant when considering a preventive approach to disability and handicap"

This statement is in line with the research findings of Heikkinen (1989) that are being discussed earlier. Williams (1995) also opined that the elderly is a group that desires a free life without being dependant on anyone to undergo their daily routines. In one of his statements:

"Most people including those who are older aim to lead an independent life. To achieve this some basic requirements and skills for day to day living are needed. These included the ability to perform personal and domestic tasks and to undertake social activities." 


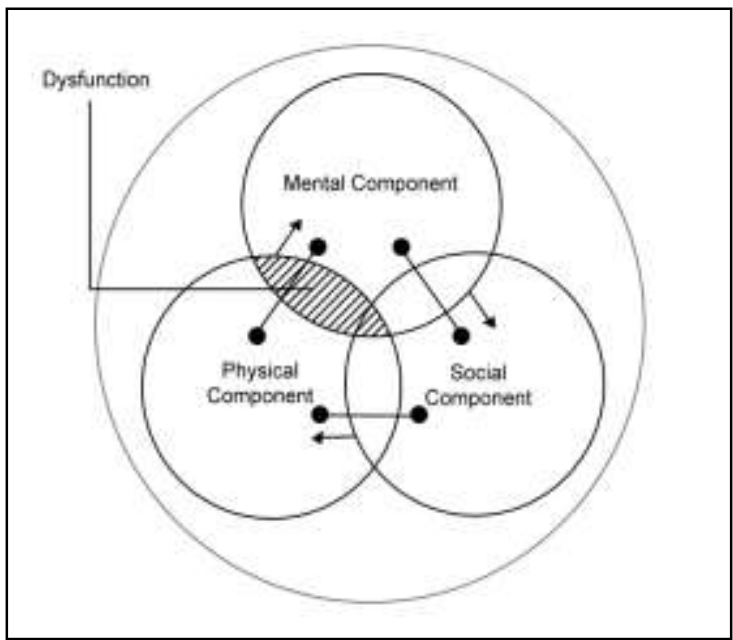

Figure 1: The Relationship between Physical, Mental and Social Components As Well As the Impact of Physical Dysfunction towards the Elderly Source: Heikkinen (1989)

Despite the physical and mental changes, the elderly still hope for an environment that will allow them to support their lives freely without being restricted by any individuals, without barriers and challenges to lead their day-to-day social lives. Kinnaird (1981) found that there are five basic needs for the elderly, which proves that the elderly as among the group with high needs for social interaction.

Williams (1995) stated that human social activities (including the elderly) is formed and based on the following factors:

- environment (refers to the quality of home environment, family structure and the number of family members)

- integration which is defined as the relationship with family, friends and local community

- communication which involves the usage of language and utilization of communication devices

- the ability to continue with daily activities (activities of daily living - ADL)

Williams (1995) has also defined the level of social activities for the elderly as needs that suits what was previously suggested by Kinnaird (1981) (Table 1 and Figure 2). Further elaboration can be seen in Figure 3.

Table 1: Types of Activities of Daily Living - ADL

\begin{tabular}{|c|l|}
\hline Type & \multicolumn{1}{c|}{ Description } \\
\hline Sociability & $\begin{array}{l}\text { Human relationship, interaction and communication with the environment for entertainment or } \\
\text { social purposes; such as visiting relatives and friends or going for a vacation }\end{array}$ \\
\hline
\end{tabular}


Othman, A.R., \& Fadzil, F. / Asian Journal of Behavioural Studies (AjBeS), 3(12) Jul / Aug 2018 (p.91-101)

\begin{tabular}{|l|l|}
\hline Domestic & $\begin{array}{l}\text { Interactions and communication for daily living purposes like cooking, washing and } \\
\text { maintenance }\end{array}$ \\
\hline Personal & For taking care of personal needs like personal hygiene \\
\hline
\end{tabular}

Source: Williams (1995)

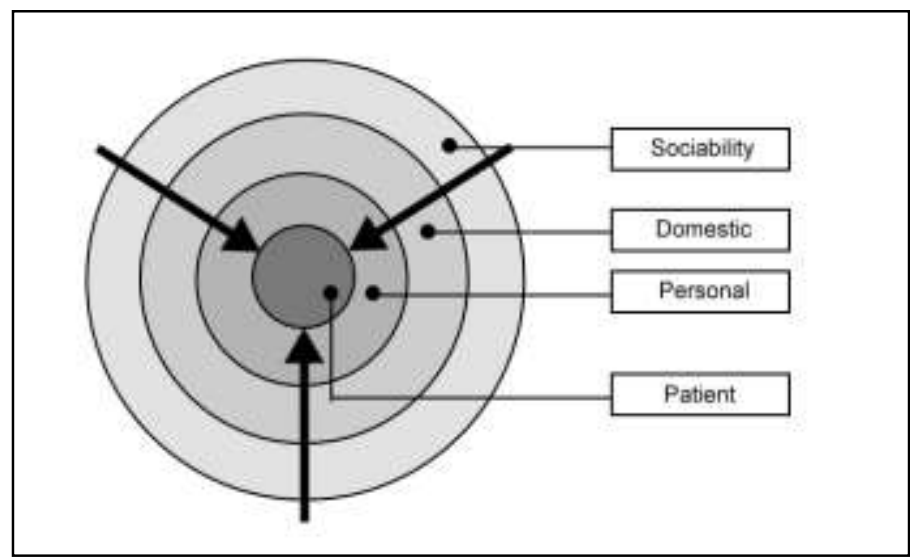

Figure 2: William's Rings Models - Social Levels of The Elderly Source: Williams (1995)

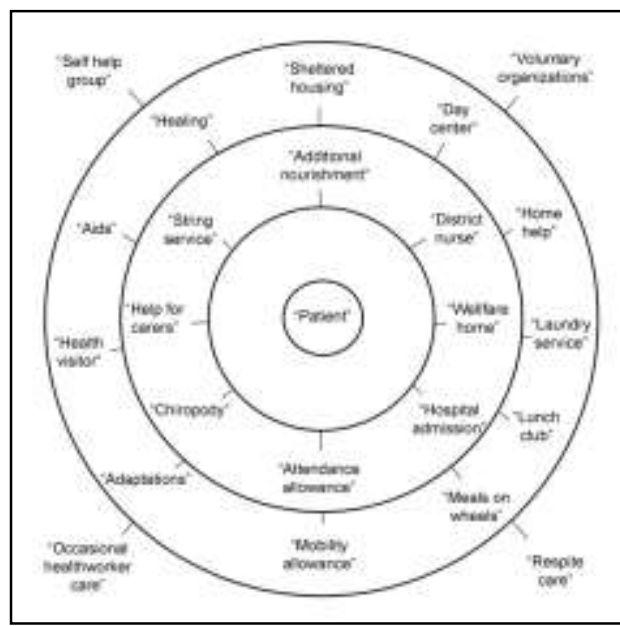

Figure 3: William's Rings Models - Services and Suitable Needs for The Elderly Source: Williams (1995) 
Based on the discussion above, it can be concluded that physiological factors and physical changes influence the mental and physical states of the elderly which will ultimately affect their lifestyles. The model of William's Rings can help in giving guidelines in the sort of social activities the elderly go through. Hence, specific designs can be created to accommodate them based on their physical and mental capabilities.

\subsection{The Importance of Outdoor Space}

Humans and nature have a bond. This attachment is clear in many things humans do:

People plant flowers and shrubs and nurture house plants; cities invest heavily in trees; citizens band together to preserve natural settings they have never seen; landscapes for centuries have been subject of painting and poetry" (Kaplan \& Kaplan, 1981).

Nature not only provides beauty both physically and visually. Having nature in proximity has many benefits according to several studies, although not only restricted to the elderly. According to Ulrich (1981), a simple task such as viewing nature in slides is enough to ease one's anxiety. He also maintains that viewing nature from windows have positive effects on physical well-being. Another research also reveals that exposure to natural settings can significantly reduce mental fatigue as well as improve self-esteem and life satisfaction (Talbot \& Kaplan 1991). The effects of nature are much deeper than its outward beauty. Recent studies show that nature has many therapeutic benefits for mankind, both physically and psychologically. Nature provides the inner sense of serenity and peacefulness (Lyle, 1985) necessary for healing. The therapeutic value of nature is not a new idea. In the 1860's and 1870's, Frederick Law Olmsted wrote his insight regarding natural settings. He professed that an environment containing vegetation or other forms of nature "employs the mind without fatigue and yet exercises it; tranquilizes it and yet enlivens it; and thus, through the influence of the mind over body, gives the effect of refreshing rest and reinvigoration to the whole system" (Ulrich \& Parsons, 1992).

\subsection{Methodology}

\subsection{Data Collection}

The data collection for this study involved observation, questionnaires and interviews.

\subsection{Observation}

Observation was done in order to assess the design, arrangement and suitability of the facilities for elderly usage, specifically, evaluation of outdoor facilities like walkway and landscaping. Apart from observation, specific measurement was also taken to be compared with the standards produced by the legal acts. This is to ensure the facilities not merely prepared but fit to be used by the elderly on a regular basis. For example, the size of doors must be at least 0.9 metres in order to ensure wheelchair users could use them, ramps must comply with the 1:12 gradient requirement and the floor must not be made by materials that 
are slippery and dangerous. Photographs were taken to serve as evidence of the observation and measurement.

\subsection{Interview with Elderly Occupants}

As many as 30 elderly occupants were selected. The level of their physical capabilities were measured based on the questionnaire set. Apart from evaluating their capabilities, this interview also served to get their personal feedbacks on the facilities provided by the elderly care centre.

\subsection{Visit and Dialogue Session}

Discussion with the administration of the elderly care centre was also held to get a clear picture of the history of establishment and the criteria of intake for the elderly occupants.

\subsection{Results and Discussions}

Mentioned earlier, the research is focusing on the outdoor facilities provided at the centre and how much it influenced the wellbeing of the elderly. The objective of this is to give a subjective assessment on the level of facilities provided in terms of the type of facilities and its quality.

\section{Case Study: Rumah Ehsan, Kuala Kubu Bharu, Selangor}

Rumah Ehsan Kuala Kubu Bharu was built on 1996 by the government to accommodate sick and non-independent elderly because of chronic diseases. During the time of the research, there are 60 elderly people living here with $39 \%$ of them being Indians, $34 \%$ Malay and $27 \%$ Chinese. The age of the occupants ranges between 58 to 82 years old.

The location is quite far from the city centre about $4 \mathrm{~km}$ from Kuala Kubu town. This area is surrounded by secondary forest that includes the golf course and vegetable farms. Neighbouring area consists of residential area, villages and institutions, the nearest public building is the Public Welfare Training Centre. It is located on the hilly area that provides good and panoramic view. This centre is divided into 2 areas, where the first being administrative area and the second being hostel area where the elderly people stay in. Both areas are connected by a bridge and the distance between them is $400 \mathrm{~m}$, hence the elderly could not reach the administrative area.

In terms of the membership policy aspect, this centre prioritizes on elderly that:

- Do not have any relatives to take care of them.

- Do not have any income and live in deprived conditions.

- Have disease (non-contagious) and unable to take care of themselves

- Age 60 and above. 


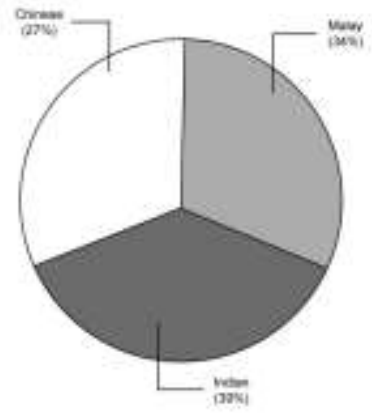

Figure 4: Demographics of the occupants in Rumah Ehsan, Kuala Kubu Bharu, Selangor Source: Rumah Ehsan's Statistics Report, 2013, Kuala Kubu Bharu

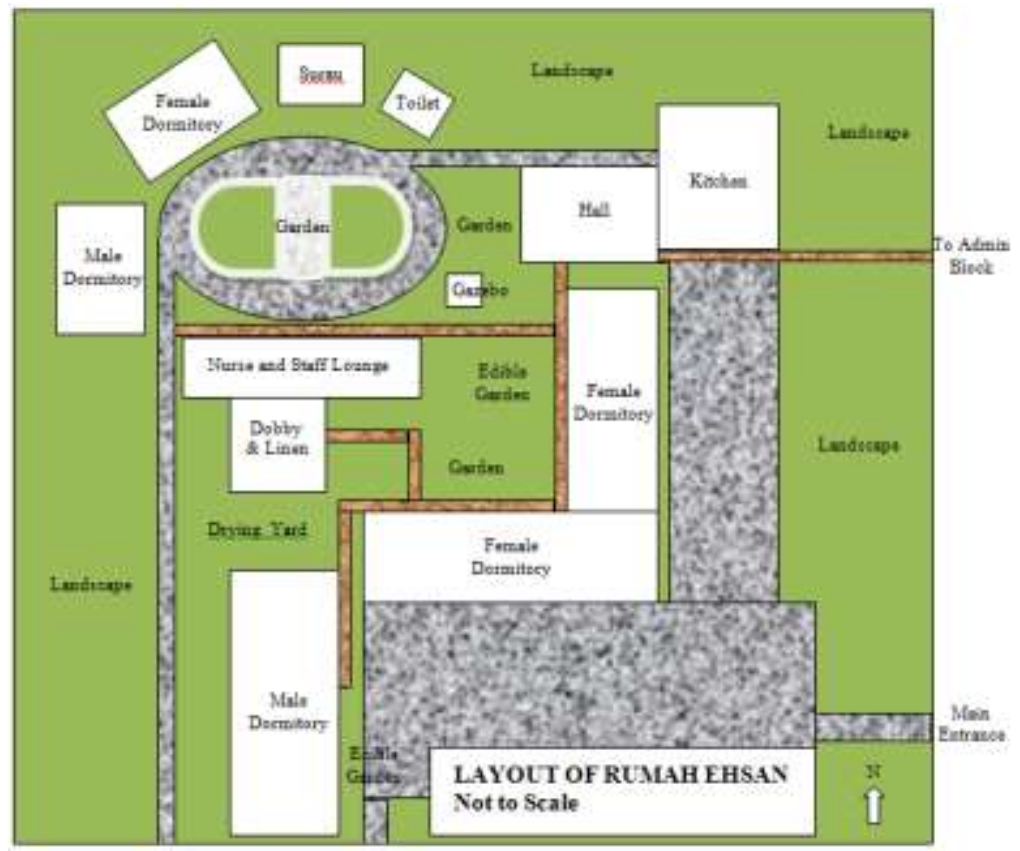

Figure 5: Layout of the Rumah Ehsan 
Figure 5 shows the overall layout of Rumah Ehsan excluding the administration block which situated on top of the hill on the east. It is linked by a covered bridge about 300 metres long for ease of circulation. However, it is a ramp up of about 15 degrees gradient that make the elderly difficult to go to the admin block on their own, especially those on wheel chair. The floor is cement rendered finish and slippery when wet. The facilities within the centre are well linked by external corridor which is covered, however, during raining season it becomes wet and slippery. On the safety aspect, the centre do provide hand rails to the corridor way. Some part of the corridor way is built on ramp, and mobility of the elderly is limited especially those on wheel chairs. The landscape among the complex is well grown and well kept by the staff at the centre. There are edible gardens at the central courtyard, initiated by the staff and the elderly are encouraged to participate in taking care of the garden. Besides gardening, the elderly are also given the chance to involve with the outdoor activities such rearing chicken, birds and fish. However, most of the occupants are too ill and their movements are limited.

Based on the questionnaire handed to the elderly of Rumah Ehsan, $70 \%$ of the elderly enjoy their outdoor spaces only by looking out of their windows. Most of them $(60 \%)$ spend only 30 minutes or less outdoors and a large number of the elderly do so in the morning $(80 \%)$. The elderly mostly answered that accessing their outdoor space is difficult especially towards those in wheelchairs $(70 \%)$. Most agreed that being outdoors make them feel healthier and happier ( $90 \%$ and $85 \%)$.

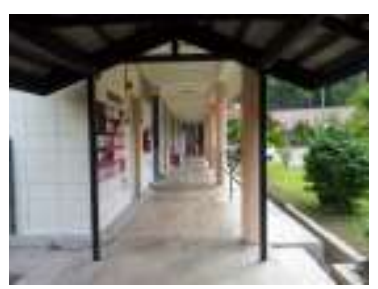

a) Corridor (but no drain cover)

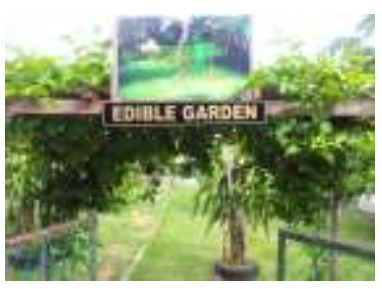

d) Entrance to Edible Garden

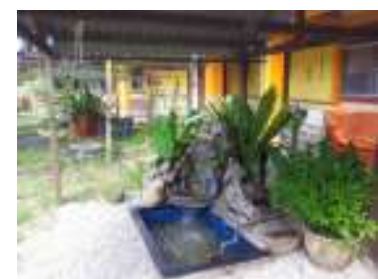

b) Small water fountain that give soothing sound

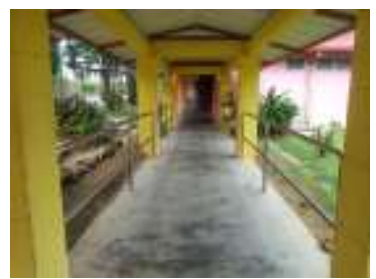

e) Corridor with handrails

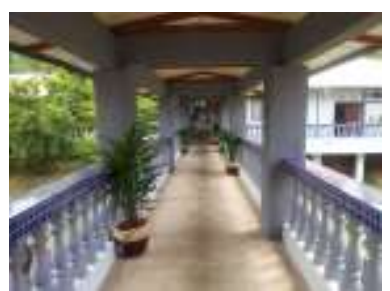

c) Bridge that link to Admin Block

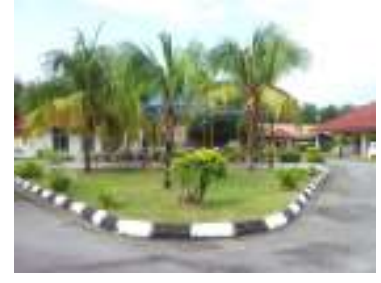

f) Well kept garden

Figure 6: Images within Rumah Ehsan complex

Figure 6 shows some of the images of within the centre. The author was not given the permission to take images in the dormitory, however, as the main focus of the 
research was concentrated on the outdoor facilities, this requirement suited well.

\subsection{Conclusion}

The growing elderly population is a major concern, not only financially, but socially as well. This not only begin to suggest the urgency in understanding how to design outdoor environments, indoors and outdoors, for the elderly.

The landscaping and greenery around the compound is well kept and these to certain extent do relieve the stress among the elderly. The sound of the water fountain, the voices of the birds and the chicken and the bustling sound of wind blowing through the courtyard give them the feeling that they used to have when they were in their home among the family members.

Contact with nature has many therapeutic benefits as established in the literature review. Provision of recreational activities for the elderly is a must for them to age successfully. A garden environment is a form of nature, and thus has all the benefits associated with nature. Activities performed within a garden environment are forms of recreation.

A successful garden environment is one that satisfies physical, psychological and social needs of the elderly people. The design needs to compensate for physical limitations that the elderly clients have so as to encourage usage by them. The design must also meet the social needs of the elderly so as to encourage them to participate in social activities.

Identifying specific environmental concerns and their related design criteria will assist the designer in providing design solutions which will encourage the elderly to use the outdoor spaces. A lot of information is available regarding outdoor spaces design for the elderly; however there is a lack of means by which to communicate this information to the designer.

\section{Acknowledgement}

The authors would like to thank Universiti Teknologi MARA and the Faculty of Architecture, Planning and Surveying for the infrastructural support.

\section{References}

Abdul Rahim, A. (2006). Keperluan Pengguna Dan Reka Bentuk Bangunan Untuk Warga Tua Di Malaysia. Malaysia: Research Centre, IIUM.

Brawley, E. (1992). Alzheimer's Disease: Designing The Physical Environment. The American Journal of Alzheimer's Care and Related Disorders and Research.

Carsten, D. (1985). Site Planning and Design for the Elderly. New York: Van Nostrand Reinhold Company.

Heikkinen, R-L. (1989). Primary Care Services for the Elderly in Six European Areas at the Beginning of the 1980s. Public Health in Europe 29, pp 75-98.

Hartig, T., Mary, M. and Gary, W. E. (1991) Restorative Effects of Natural Environment Experiences. Environment and Behaviors 23.1: 3-26. 
Hershberger, G., Cathy, L., and Harris J. (1977) "Use of Gerontological Research Information in a Design Studio" Journal of Architecture Education 31: 33-36.

Howell, S. C. (1980). Designing for the Aging: Patterns of Use. Cambridge, MA: The MIT Press.

Kaplan, R. and Kaplan, S. (1991) Restorative Experience: The Healing Power of Nearby Nature. Cambridge, MA: The MIT Press.

Lawton, M. P. (1990). Residential Environment and Self-Directedness Among Older People. American Psychologist 45:5: 638-640.

Lovering, M. J. (1990). Alzheimer's Disease and Outdoor Space: Issues In Environmental Design. The American Journal of Alzheimer's Care and Related Disorders and Research.

Lyle, J. T. (1985). Design for Human Ecosystems: Landscape, Landuse and Natural Resources. New York: Van Nostrand Company.

Malaysian Standard MS 1331, 1993 - "Code of Practice for Access for Disabled People Outside Buildings"; Standards \& Industrial Research Institute of Malaysia.

Malaysian Standard MS 1184, 1991 - "Code of Practice for Access for Disabled People Outside Buildings"; Standards \& Industrial Research Institute of Malaysia.

Malaysian Standard MS 1183, 1990 - "Specifications for Fire Precautions in the Design and Construction of Buildings Part 8: Code of Practice for Means and Escape for Disabled People"; Standards \& Industrial Research Institute of Malaysia.

Talbot, J. F. and Kaplan, R. (1991). The Benefits of Nearby Nature for Elderly Apartment Residents. 33:2: 119-130. Ulrich, R. S. (1981). Natural Versus Urban Scenes: Some Psychological Effects. Environment and Behavior 13.5:523-556.

Ulrich, R. S. (1984). "View Through a Window May Influence Recovery from Surgery" Science 224: 420-421.

Williams. E.I. (1995) Caring for Older People in the Community. 3rd edn. Radcliffe, Oxford. 